\title{
Estructura fiscal y protección social: Economía política de los privilegios en Paraguay
}

\section{Tax structure and social protection: Political economy of privilege in Paraguay}

\section{Luis Ortiz ${ }^{a}$}

\begin{abstract}
Resumen
El efecto de incertidumbre generado por la emergencia sanitaria debido a la pandemia, con sus restricciones impuestas por el confinamiento, llevó a los sectores sociales desfavorecidos a caer en situaciones de extrema vulnerabilidad. La incapacidad del poder público de atender las necesidades que surgieron en este escenario, puso al desnudo la estructura de los privilegios en Paraguay, resultante de la concentración económica y la captura del Estado por los sectores sociales dominantes. La fragilidad de los servicios públicos, en especial los previsionales, para responder las demandas de protección social se explica especialmente por su bajo financiamiento con recursos genuinos del tesoro público, dado un sistema impositivo regresivo cuyo diseño es impuesto por los sectores dominantes reflejando la estructura social. La posibilidad de modificar los rasgos de esta última, es presionando por cambios en la estructura fiscal, constituyendo el principal desafío de las acciones colectivas.
\end{abstract}

Palabras clave: pandemia, privilegios, presión social, estructura fiscal, protección social, acción colectiva.

\begin{abstract}
The effect of uncertainty generated by the health emergency due to the pandemic, with its restrictions imposed by confinement, led the disadvantaged social sectors to fall into situations of extreme vulnerability. The inability of the public power to meet the needs that arose in this scenario, exposed the structure of privileges in Paraguay, resulting from economic concentration and the capture of the State by the dominant social sectors. The fragility of public services, especially social security, to respond to social protection demands is explained especially by their low financing with genuine resources from the public treasury, given a regressive tax system whose design is imposed by the dominant sectors, reflectingthe social structure. The possibility of modifying the characteristics of the latter is by pressing for changes in the tax structure, constituting the main challenge of collective actions.
\end{abstract}

a Instituto de Ciencias Sociales, Paraguay.

Correspondencia a: l.ortizs@yahoo.com

Recibido:

23 de agosto de 2020

Aceptado:

3 de noviembre de 2020

\section{(c) (i)}

Artículo publicado en acceso abierto bajo la Licencia Creative Commons.

Cita:

Ortiz, L. (2020). Estructura fiscal y protección social: Economía política de los privilegios en Paraguay. Kera Yvoty: reflexiones sobre la cuestión social, 5, 11-23 
Keywords: pandemic, privileges, social pressure, tax structure, social protection, collective action.

\section{Introducción}

Toda la historia de los regímenes desiguales muestra que son sobre todo las movilizaciones sociales y políticas, las experimentaciones concretas las que permiten cambiar la historia Thomas Piketty

Enépocas en queuna crisis pandémica instala múltiples incertidumbres y en que se desnudan las fragilidades de las instituciones para enfrentar el riesgo, la interpelación a la capacidad del poder público para proteger la población, es imperiosa. Y, para las ciencias sociales, obligatoria. Más aún porque, a pesar de la concepción de sentido común, el bienestar social no es producto de la buena voluntad individual sino una responsabilidad colectiva.

En Paraguay, las (pocas) instituciones
sociales que tienen por objetivo proteger frente al riesgo presentan dos principales limitaciones: su debilidad y su fragmentación. Y las causas de esto se hallan en las relaciones sociales detrás del ejercicio del poder. Si un sistema de protección social es la institucionalización de las relaciones de solidaridad, la traba para la instauración de ese sistema es producto de relaciones contrarias y corrosivas a la solidaridad.

Nuestra hipótesis es que la solidaridad social no se institucionaliza en el país como sistema de protección porque amenaza la estructura de poder. Su instauración requiere afectar la estructura fiscal, núcleo duro de la captura del Estado por las clases propietarias ${ }^{1} y$ base de la desigualdad social.

1 Hay detrás de la noción de "élite" una concepción
implícita entre muchos cientistas sociales paraguayos
según la cual creen designar a los sectores sociales
dominantes, eludiendo la fuerza heurística y crítica
del concepto de clase social. Este eufemismo adolece
de abordar la concentración del poder por las clases
propietarias como si fueran élites, es decir, grupos
con función dirigente, que adscriptas a varias clases
(medias y superiores) y cuya característica es su
impronta intelectual, disponen de un proyecto
social integral del que persuade a la población. Al
La reforma tributaria hacia un sistema impositivo progresivo es así el fundamento de un cambio sustantivo de la estructura de privilegios y las relaciones de poder.

\section{Estructura productiva y estructura social}

En el análisis de los alcances y límites de la protección social, es necesario entender la totalidad social en que se desenvuelven las relaciones dinámicas entre la estructura productiva, la estructura fiscal y la estructura social, para articularse en una forma histórico-concreta de poder.

En lo concerniente la estructura productiva paraguaya, sus tres rasgos centrales son la heterogeneidad de la productividad entre las ramas de actividad económica, la segmentación del mercado de trabajo en detrimento de la productividad, y, la inamovible desigualdad social.

Según las estadísticas oficiales para el periodo interquinquenal 19972017, el grupo de las ramas de actividad de mayor absorción de población ocupada está constituido por la rama agropecuaria, seguida del comercio y la hospitalidad, luego de los servicios personales y comunales, para ocupar la manufactura/industria el cuarto lugar (Figura 1). Las restantes ramas albergan significativamente menor población ocupada en sus unidades productivas. 


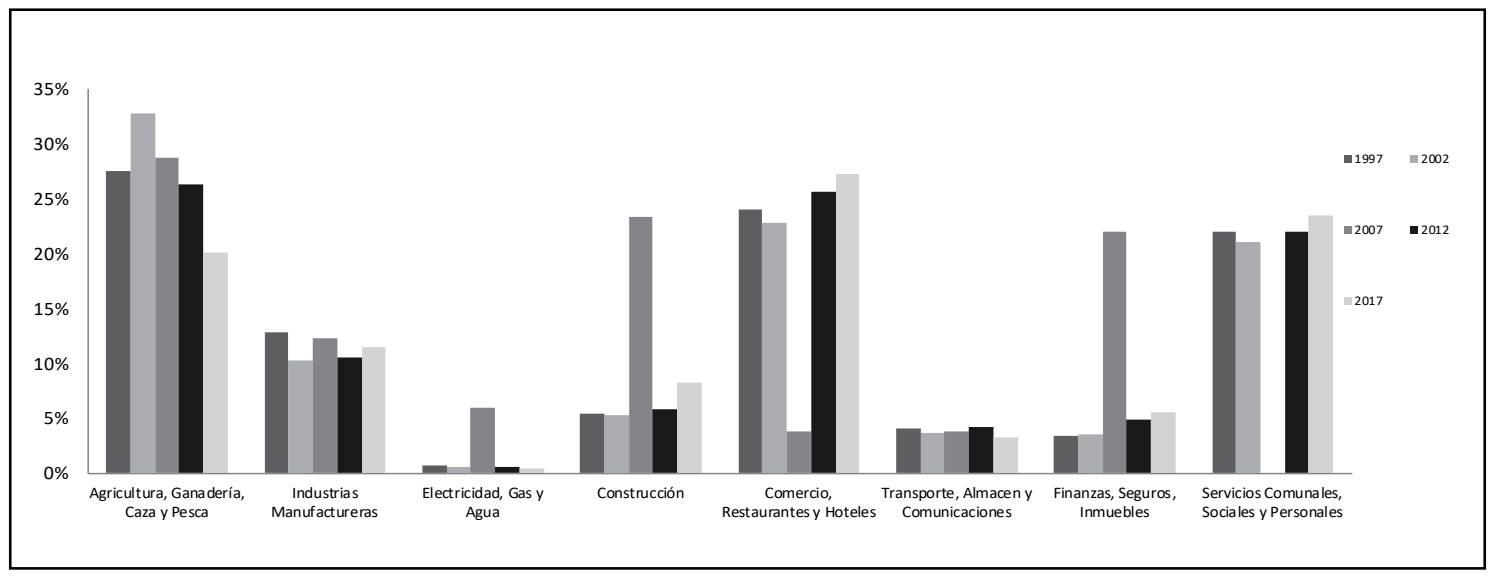

Figura 1. Proporción de la población por rama de actividad, periodo 1997-2017.

Fuente: Elaboración propia con base en encuestas de hogares (EPH) 1997-2017, DGEEC.

Las ramas económicas con mayor volumen de población ocupada se caracterizan por su relación inversa con los niveles de escolaridad (Figura 2). La rama de la producción agropecuaria cuenta con las medias de escolaridad más reducida seguida del sector industrial, luego del comercio y hospitalidad. En contrapartida, las ramas con menos volumen de población ocupada presentan las medias más altas de escolaridad: finanzas, energía y logística.
Esas mismas ramas, a saber, la de energía, de finanzas y de logística (en este orden) cuentan con los niveles de ingresos per cápita más elevados, seguidas mucho después, en igual proporción, por las ramas de servicios y la industrial respectivamente (Figura 3). Por tanto, la productividad laboral elevada en estas últimas ramas resulta del mayor nivel educativo y de retribución al trabajo, con un volumen de población ocupada más bajo que en

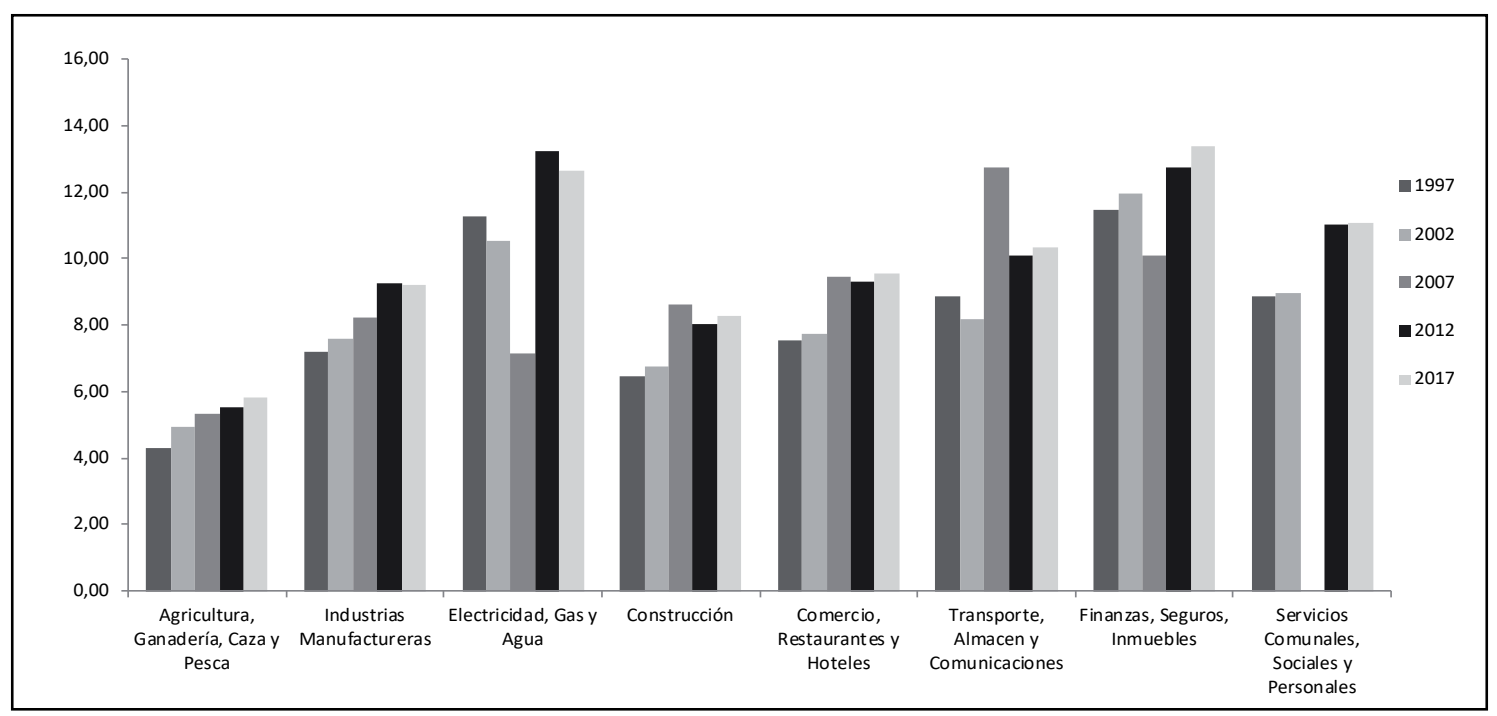

Figura 2. Medias por años de estudios por rama de actividad, periodo 1997-2017.

Fuente: Elaboración propia con base en encuestas de hogares (EPH) 1997-2017, DGEEC. 


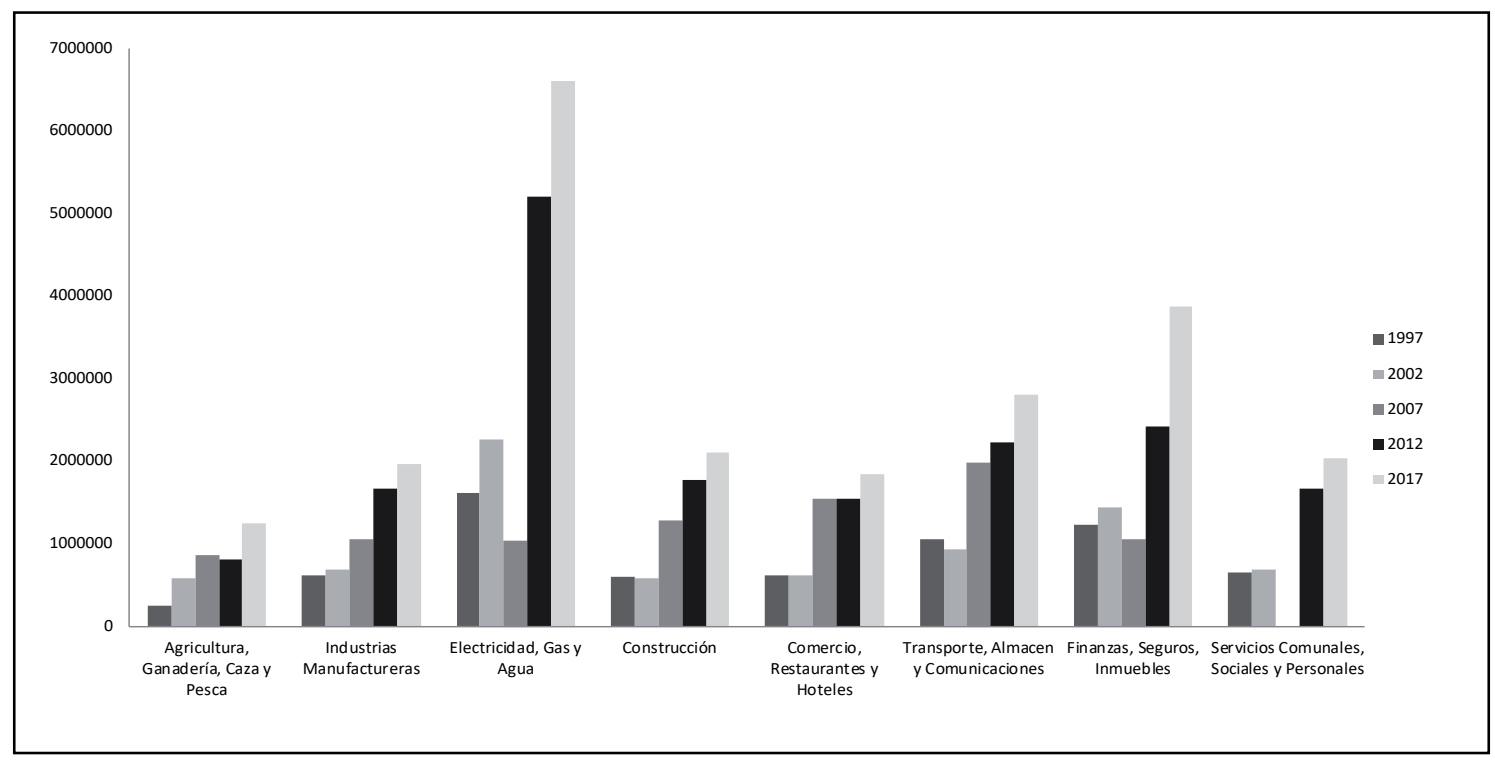

Figura 3. Medias ingresos por rama de actividad, periodo 1997-2017.

Fuente: Elaboración propia con base en encuestas de hogares (EPH) 1997-2017, DGEEC.

las demás ramas de la economía. De este modo, el valor del producto es superior en las ramas económicas cuya productividad laboral -como proxy de la productividad total de los factores- es más elevada.

Ahora bien, la rama de actividad agropecuaria presenta una especificidad en el análisis. A diferencia de las otras, ella abriga en su seno la mayor diferenciación entre las unidades económicas. ${ }^{2}$ Este rasgo del sector primario tiene lugar en una estructura agraria en el que el percentil más elevado de la población propietaria se alza con el $84 \%$ de la propiedad. Por tanto, dado el carácter monopólico del capitalismo agrícola, la rama agropecuaria genera valor "cuya contribución al PIB es del orden de $25 \%$; vale decir, representa un cuarto de la producción global de la economía

2 La población ocupada de forma unipersonal o en unidades de no más de 10 personas (microestablecimientos) alcanzan un $75 \%$ del total, con un ingreso monetario medio que representa 10 veces menos de la población ocupada en establecimientos de 10 a 49 personas e incluso 30 veces menos de la población ocupada en establecimientos de 50 personas y más (DGEEC, 2018). El primer rango de fincas corresponde a los labriegos de la agricultura familiar campesina. paraguaya" (Borda y Caballero, 2016).

En la distribución de los ingresos según las categorías socioocupacionales, los patrones de empresas y los grandes propietarios agrícolas concentran el ingreso a un punto que la distribución presenta la apariencia de similitud entre todas las categorías que quedan por debajo de ella (Figura 4). La tendencia de la distribución de los ingresos se expresa, para dicha categoría, en una curva creciente que desde el año 2013 aumentó exponencialmente, verificándose magnitudes medias anuales que superan casi cincuenta veces a la categoría inferior de toda la estructura socioocupacional, a saber, de los productores de la agricultura familiar campesina. Este proceso se explica por el modelo de crecimiento que se concentró en las ramas de actividad de productividad elevada y que relegó a las ramas de baja productividad, por lo tanto, con marcada diferenciación interna y desigualdad de los dividendos (Ortiz, 2019).

En suma, las ramas de actividad de elevada productividad albergan grosso modo el segmento formal del mercado de trabajo mientras que las ramas de baja 


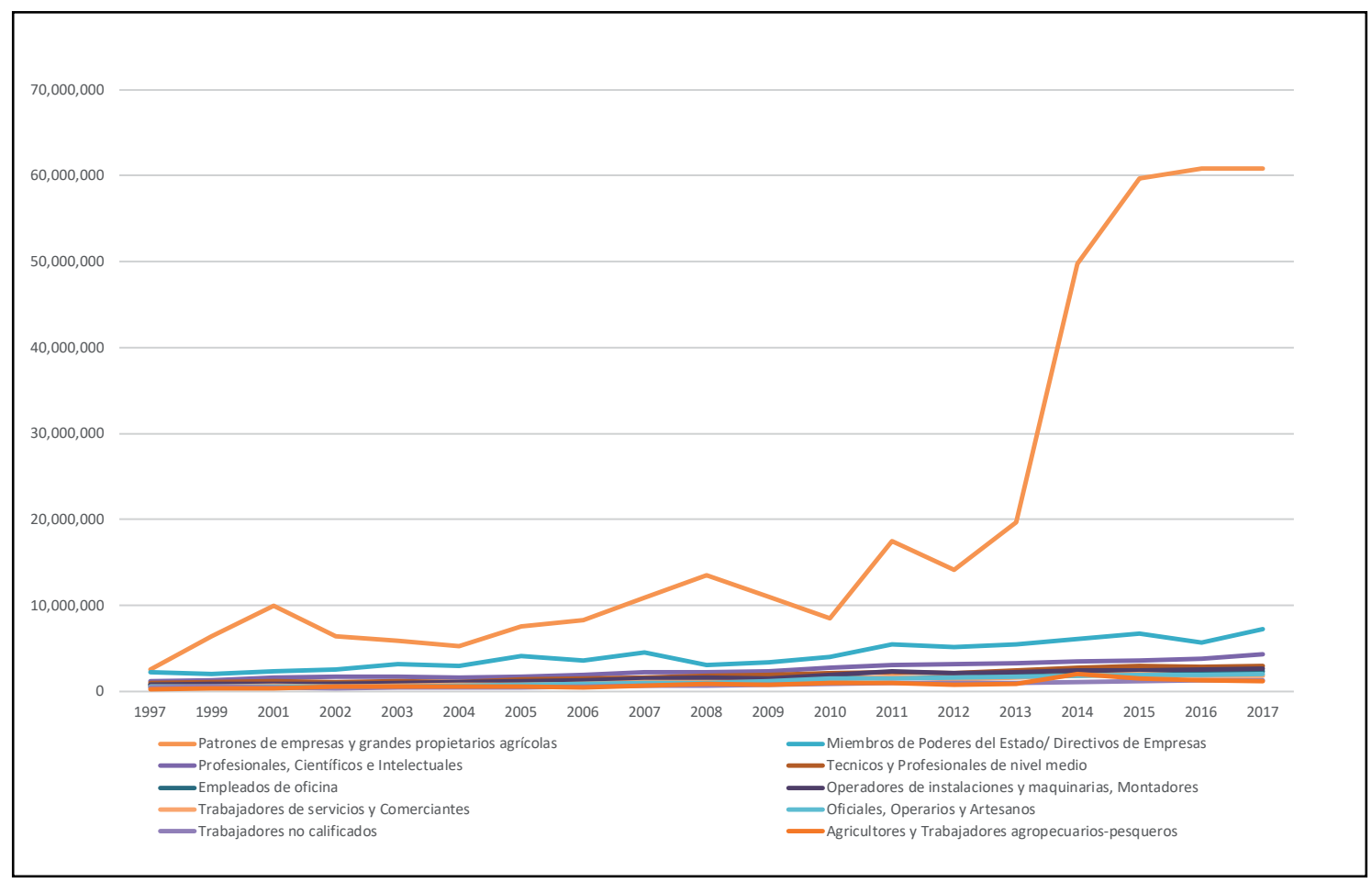

Figura 4. Categorías socioocupacionales según ingresos medios, 1997-2017.

Fuente: Elaboración propia con base en encuestas de hogares (EPH) 1997-2017, DGEEC.

productividad concentran las del segmento informal. En esta estructura productiva, heterogénea, las fuentes de empleo se dispersan en nichos competitivos (enclaves) y nichos de bajos niveles de productividad, estableciendo una disociación en el mercado de trabajo entre dos segmentos muy desiguales: el segmento formal donde una minoría de la PEA se emplea en puestos de trabajo con salario mínimo y con seguridad social mientras que, en contrapartida, en el segmento informal la mayoría de la PEA se emplea sin salario mínimo, sin seguridad social y vulnerable a los riesgos.

Esta segmentación del mercado de trabajo funciona como una limitación estructural para el aumento de la productividad, dada una oferta laboral abundante y una demanda laboral escasa, condición para el control, por parte de los empleadores, del aumento de los salarios ("efecto población de reserva" según Marx). Además del rezago de la productividad del trabajo en el segmento informal, la heterogeneidad estructural es la causa de la desigualdad social debido a las retribuciones desiguales de la fuerza de trabajo entre uno y otro segmento.

El rasgo principal de la estructura productiva paraguaya en las dos primeras décadas del siglo XXI, fue el de la estructuracióndesigualdesuproductividad. Esto se debe a que no requirió la separación decisiva de los productores directos de sus condiciones de producción, sino implicó un proceso ambiguo: por una parte, un sistema de producción minifundista con pequeños propietarios excluidos de la acumulación $y$, por otra parte, un extendido sistema de trabajo no mercantilizado en el que la población rural excedente se urbanizó con la marginalización de sus condiciones 
de vida. ${ }^{3}$ Entender este proceso de disponibilidad de la fuerza laboral para el mercado de trabajo es clave para entender la acumulación y su efecto en la estructura social.

Dada estas características de la estructura productiva, los diferentes sectores sociales toman modalidades desiguales de inserción en el mercado de trabajo, adquiriendo posiciones sociales diferenciadas y jerárquicas en la sociedad, al punto que la desigualdad es insensible a los esfuerzos de movilidad social. ${ }^{4}$ En términos empíricos el efecto de cierre social (Weber, 1964) es un rasgo que las clases propietarias paraguayas confieren a la estructura social sirviéndose de su posición dominante para evitar la modificación de sus privilegios. ${ }^{5}$

\section{Estructura social y estructura fiscal}

No hay un indicador más inequívoco de la forma institucional que adquieren las relaciones de poder que la estructura fiscal. En Paraguay, ésta cumple la función de consagrar el derecho de propiedad sin el recurso directo a la coerción. ${ }^{6}$

3 A partir de los años noventa del siglo XX, el debilitamiento del movimiento sindical o desindicalización fue resultado de dos procesos: la aguda desmercantilización del trabajo como efecto de las políticas neoliberales y la cooptación de las dirigencias sindicales - con la aquiescencia de éstasdada la escasez progresiva de oportunidades sociales. 4 Si contamos las primeras cohortes de egreso de la reforma educativa de los noventa (2005 en adelante) y las primeras cohortes de egreso en la educación superior de esa generación (2010 hasta la fecha), hay una proporción significativa de población, especialmente urbana, que aumentó su volumen de credenciales, pero cuyo acceso al trabajo se vio limitado. Por ello, la función pública como nicho de absorción de la fuerza laboral calificada, fue crecientemente demandado y objeto de disputa. Las acciones colectivas por la transparencia y el mérito revelan así un conflicto en la búsqueda de movilidad social.

5 Verónica Serafini sostiene que una de las causas de la desigualdad se halla en la captura del Estado por grupos empresariales que, buscando la promoción de sus intereses, socavan un proyecto de bienestar colectivo (Serafini, 2017)

6 Según Norbert Elías (2011), el monopolio fiscal es la institución por medio de la cual el Estado instituye legalmente la contribución compulsiva y funda el
Apuntalando la propiedad privada, favorece la concentración de capital, restringe el ajuste de la fuerza de trabajo a las condiciones mínimas de su reproducción social y alimenta un sistema clientelista de relaciones políticas.

Instituida por las clases propietarias, la estructura fiscal paraguaya establece un sistema de contribución impositiva que transfiere el costo económico de la convivencia social a los sectores sociales desfavorecidos. Esta transferencia de responsabilidad fiscal, no toma la forma abierta que adquiría en los regímenes monárquicos, sino que toma la forma disimulada de una contribución elusiva, o sea una imposición menor relativa a la de los demás sectores sociales.

La estructura fiscal, entendida como la distribución de la contribución impositiva según las clases sociales, impone cargas concretas por cada categoría tributaria. Así los impuestos sobre los ingresos y el patrimonio (impuestos directos) que tasan a las clases propietarias, representan una carga significativamente menor que los impuestos sobre el consumo de bienes y servicios (impuestos indirectos) que tasan a las clases medias y populares, con una elevada carga tributaria. Con una media de $21,8 \%$ de contribución al fisco de los impuestos directos y $78,2 \%$ de los indirectos respectivamente, la desigualdad de la imposición está inversamente asociada a la desigualdad de la retribución (Borda y Caballero, 2018). ${ }^{7}$

tesoro nacional, imponiendo por fuerza un poder público concentrado. Por ello es un poder impositivo. Además de la violencia física para el resguardo de la soberanía territorial y disuadir de la guerra civil, el Estado tiene otras funciones como precautelar la seguridad pública (integridad física), la seguridad civil (derecho de propiedad) y, más recientemente, la seguridad social (derecho de inclusión).

7 La categoría del impuesto a la renta (IR), que abarca la totalidad de los impuestos directos en Paraguay, se clasifica en el impuesto a la renta a las actividades comerciales, industriales y de servicios (IRACIS) y que contribuyó en el periodo 2010-2015 con una media del 9o\% del total de la recaudación de la categoría, seguida del impuesto a la renta agropecuaria (IRAGRO) con una contribución del 5,4\% entre el 
En lo que concierne a la carga tributaria indirecta y su relación con los niveles de ingresos, se verifica que el decil superior de la población tributa en IVA sólo el $2 \%$ de la totalidad de sus ingresos, mientras que el decil inferior de la población tributa en IVA el $13 \%$ de la totalidad de sus estipendios (Barreix, 2016). Es decir, transfiriendo la carga impositiva a los sectores sociales desfavorecidos, la estructura fiscal opera como una fuente de extracción de excedente del trabajo organizando la contribución impositiva en razón inversa al volumen de los ingresos (Rodríguez, 2019; Palau, 2016).

Con una baja presión tributaria (12,7\% del PIB) "el Estado paraguayo presenta deficiencias de recursos para la implementación de políticas públicas de todo tipo" (Duarte, 2017, p. 57). En correspondencia, con una elevada presión burocrática $\left(62 \%\right.$ de los IF) ${ }^{8}$ el acceso a la administración pública tuvo lugar bajo la forma de clientelismo plural (Schuster, 2013).

La estructura fiscal desnuda que, contribuyendo de modo irrisorio en la masa impositiva, los agentes del capital capturan rentas como forma de acumulación capitalista. Esto tiene un significado político crucial: el Estado se asienta sobre una contradicción entre el modo de acumulación y el modo de reproducción produciendo las condiciones

2014 y el 2015, luego el impuesto a la renta personal (IRP) con una contribución de apenas el $2 \%$ del total y, por último, el resto de pequeñas categorías como el impuesto a la renta de los pequeños contribuyentes que con otros impuestos menores aportaron el $5 \%$ del total de la recaudación de la categoría en el mismo periodo (Borda y Caballero, 2016). La disimulación de la contribución de los propietarios del capital, a través del IRACIS -y no del IRP- muestra cómo la clase propietaria opera con determinación para delinear el sistema impositivo y favorecerse a sí misma, eludiendo su responsabilidad frente a la sociedad por transferir a sus establecimientos sus obligaciones como agentes individuales de clase.

8 Proporción de ingresos tributarios destinados al gasto de sostenimiento de la administración, descontando las contribuciones a la seguridad social (Abente, 2012). de desgaste de su propia legitimidad. Para resolver esta contradicción, las clases propietarias y el Estado (capturado por aquellas) instituyeron y alimentan un sistema político clientelista para el cual la burocracia pública sirvió durante más de setenta años a cristalizar los intereses propietaristas en la estructura fiscal. Sin la burocracia esta estructura no hubiera tenido "fuerza de ley". ${ }^{9}$

La forma específica de acumulación de capital, a través del dumping impositivo, produce una estructura social de persistente desigualdad, que se mantiene sobre extendidas necesidades sociales insatisfechas. El elevado nivel de exclusión social se vuelve, para la población que no cotiza en un sistema previsional -público o privado-, una condición de vulnerabilidad ante los riesgos y, con una ingente demanda previsional, se debate entre resignarse a la estructura de podery su sistema clientelista, o impugnarlo a través de acciones colectivas contenciosas.

\section{Demanda previsional y presión social}

Denominaremos presión social a la demanda previsional dirigida al poder público. Demanda que no sólo concierne el acceso a servicios sino también traduce la necesidad de una redistribución del producto del crecimiento. La presión social interpela la estructura de poder, en primer lugar, porque disputa los recursos y oportunidades para la población desprotegida, modificando su distribución $y$, en segundo lugar, porque apunta a la conquista y extensión de derechos, aumentando el control institucional sobre los privilegios.

\section{La desprotección social opera,}

\footnotetext{
9 Ésta fue la función compartida de tres fuerzas monopolistas en Paraguay: el monopolio de la violencia (el estamento militar), el monopolio fiscal (la burocracia) y el monopolio económico (las clases propietarias). El Partido Colorado se constituyó en el actor que articuló a modo de "unidad granítica" las tres fuerzas en un sistema clientelista de poder público.
} 
Tabla 1. Indicadores de calidad del trabajo de la población ocupada (18 años o más) (\%).

\begin{tabular}{|c|c|c|c|c|c|c|c|c|c|}
\hline \multirow[b]{2}{*}{ Indicadores } & \multicolumn{3}{|c|}{ Total } & \multicolumn{3}{|c|}{ Urbana } & \multicolumn{3}{|c|}{ Rural } \\
\hline & $\stackrel{\pi}{0}$ & $\begin{array}{l}\stackrel{y}{0} \\
\hat{0} \\
\text { हี }\end{array}$ & 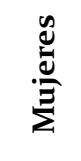 & $\stackrel{\pi}{0}$ & 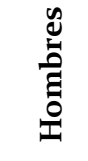 & 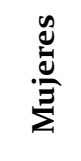 & $\stackrel{\pi}{0}$ & 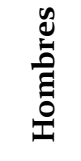 & 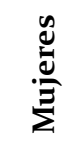 \\
\hline $\begin{array}{l}\text { No aporta a ningún } \\
\text { seguro médico }\end{array}$ & 68,2 & 70,2 & 65,3 & 60,2 & 62,2 & 57,6 & 82,6 & 83,1 & 81,9 \\
\hline $\begin{array}{l}\text { No aporta a ningún } \\
\text { mecanismo de } \\
\text { jubilación }\end{array}$ & 77,3 & 77,1 & 77,8 & 71,2 & 70,7 & 72 & 88,2 & 87,2 & 89,9 \\
\hline $\begin{array}{l}\text { Asalariados/sin } \\
\text { contrato escrito }\end{array}$ & 40 & 47,1 & 24,3 & 35,3 & 42 & 22,9 & 54,6 & 60,7 & 31,8 \\
\hline Subempleo* & 19,2 & 16,7 & 23 & 19,9 & 16,9 & 23,9 & 18 & 16,3 & 21 \\
\hline
\end{tabular}

Fuente: Serafini et al. (2019).

económicamente, como una forma de descapitalización: se coarta el desarrollo productivo por la escasez de inversión en capital humano. ${ }^{10}$ Esta especificidad paraguaya del capitalismo subsidia impositivamente a las clases propietarias y transfiere a la población restante los costos de la reproducción por sí misma (v.gr. el "sistema de protección de rifas y polladas"). En efecto, la cuestión de la protección social, antes que un problema de financiamiento o de descoordinación, es un problema redistributivo. Redistribución que afecta, fundamentalmente, la lógica contributiva. Ante un cambio en la distribución de las cargas tributarias entre las clases (o cambio en la estructura fiscal), una reducción de la intensidad de la desigualdad tiene el potencial de modificación de la estructura social.

La estructura fiscal vigente dificulta el ajuste de la fuerza de trabajo a las condiciones de su reproducción. Esto

10 Impidiendo la transformación de la estructura productiva, la distribución homogénea de la productividad en todas las ramas de la actividad económica y la reducción de la desigualdad social. significa que la política de bienestar se reduce al sistema previsional del mercado de trabajo, asimismo que atiende solamente una quinta parte de la PEA ocupada. Así también esa política suministra servicios descoordinados y focalizados a sectores sociales fragmentados, impidiendo la institucionalización de un sistema universal de protección social.

La previsión social es un sistema precario: en el año 2017 el $70 \%$ de la población ocupada ganaba menos del salario mínimo legal, sólo el 6o\% de la población asalariada contaba con un contrato escrito de trabajo, el $23,3 \%$ de esa población aportaba al seguro previsional de salud y sólo el $22,7 \%$ cotizaba a un fondo previsional de jubilación (Serafini et al., 2018, pp. 99-102). Si, por la vía del mercado de trabajo, la mayoría de la población económicamente activa no asegura las funciones mínimas de reproducción, otros aspectos como el desempleo, la crianza y el bienestar infantil, el subsidio integral de escolaridad, el acceso a la vivienda, el cuidado en la vejez y la invalidez, así como la licencia por maternidad, quedan en general descubiertos por las instituciones 
públicas de bienestar o cubiertos de modo exiguo."

Entre las instituciones cruciales de protección social, el sistema de salud cumple las funciones de prevenir, tratar y rehabilitar a las personas en situaciones de morbilidad, así como promueve el resguardo de la vida. Este sistema en Paraguay es el único que no atravesó por una reforma sustantiva a lo largo del proceso de democratización. Hubo cierta modificación de sus componentes y cierta extensión de la cobertura, pero el modelo continuó incólume.

Un problema del sistema es su segmentación. Hay dos esferas institucionales de atención (pública y privada) entre las cuales la esfera privada proporciona una oferta cuya calidad está sujeta a las disparidades propias del mercado, mientras que la esfera pública provee una oferta cuya calidad depende de la inversión de recursos públicos, contingentes según el poder político. La segregación social que el sistema asistencial de salud produce, refuerza las desigualdades.

Otro problema del sistema es su fragmentación, "que se da cuando los diversos subsistemas no operan en forma coordinada y sinérgica, impide una estandarización adecuada de la calidad, contenido, costo y aplicación de las intervenciones" (Zavattiero, 2019, p. 63).

Asimismo, un problema del sistema es la desarticulación entre los niveles de complejidad. Según la proximidad o no con la zona metropolitana asuncena, el acudimiento a unidades de salud de

11 El cumplimiento de estas funciones como expresión de la solidaridad social, en un sistema de universal, desmercantilizado y de titularidad pública es su principio institucional. Supone que, al igual que la seguridad social se despliega por un sistema solidario de repartición en el cual la población activa sostiene a la población retirada, la protección social se establece por un sistema solidario, de redistribución, en el cual la población privilegiada sostiene a la población desfavorecida. El derecho de ciudadanía y no el tutelaje estatal -paternalista y clientelar- es su fundamento ético político (García, 2015). proximidad es frecuentemente eludido para usufructuar establecimientos de segundo y tercer nivel, congestionando los servicios y forzando a una distribución presupuestaria inequitativa entre los niveles. Siendo el sistema de atención primaria de salud, una instancia clave de cobertura asistencial, el número de unidades de salud es aún deficitarioy hay sectores de la población que no están cubiertos. Según Zavattiero, en el año 2016 las unidades de salud de la familia cubrían sólo un $32,7 \%$ de la población y aunque el diseño de la estrategia planteó que la concentración de esas unidades se ajustara a la densidad demográfica en los puntos del territorio nacional con mayor incidencia de pobreza, el déficit asistencial aún persiste, más allá del despliegue de inversión e infraestructura (Zavattiero, 2019, p. 66).

En suma, la política de salud pública genera una segmentación del sistema, dispersa los recursos, segrega socialmente la población y fragmenta la planificación.

La oferta pública es predominante en el sistema. Los servicios asistenciales en el año 2015 fueron cubiertos por el Ministerio de Salud Pública y Bienestar Social en una proporción del $59,2 \%$ de la población que reportó alguna situación de enfermedad o accidentes. Dicha cifra aumentó 14 puntos en el decenio 2006-2015 (DGEEC, 2016 citado por Zavattiero, 2019, p. 71).

No es casualidad que en un periodo que comportó uno de los ciclos de mayor crecimiento económico, la demanda efectiva de asistencia en salud se haya duplicado. El aumento del producto de las actividades agropecuarias tecnificadas, altamente contaminantes, generó no sólo sus beneficiarios sino también sus víctimas. La degradación ambiental producida por el modelo agroexportador resultó en el incremento de la proporción poblacional que, en situación de morbilidad, acudió a algún servicio asistencial. La demanda pasó del $48,4 \%$ en el año 2000 al $84,3 \%$ de previsión en el año 2020, es decir un incremento de casi el 100\% (Zavattiero, 2019). Asimismo, el 15,7\% que no acudió 
Ortiz, L. Estructura fiscal y protección social: Economía política de los privilegios en Paraguay.

Tabla 2. Promedio de ingresos mensuales (en miles de guaraniés) por quintiles de ingresos per cápita mensual, según fuente de ingreso, año 2017

\begin{tabular}{|c|c|c|c|c|c|c|}
\hline \multirow{2}{*}{ Fuente de ingreso $^{1}$} & \multirow{2}{*}{ Total } & \multicolumn{4}{|c|}{$\begin{array}{l}\text { Hogares clasificados por quintiles de } \\
\text { ingreso per capita mensual }\end{array}$} & \multirow[b]{2}{*}{$\begin{array}{c}20 \% \\
\text { más rico }\end{array}$} \\
\hline & & $\begin{array}{c}20 \% \\
\text { más pobre }\end{array}$ & $\begin{array}{c}20 \% \\
\text { siguiente }\end{array}$ & $\begin{array}{c}20 \% \\
\text { siguiente }\end{array}$ & $\begin{array}{c}20 \% \\
\text { siguiente }\end{array}$ & \\
\hline Ingresos laborales & 4.604 & 1.028 & 2.118 & 3.118 & 4.410 & 9.686 \\
\hline Ing por ayuda familiar del país & 745 & 378 & 561 & 585 & 911 & 1.371 \\
\hline $\begin{array}{l}\text { Ing por ayuda familiar del } \\
\text { exterior }\end{array}$ & 624 & 214 & 262 & 396 & 587 & 1.522 \\
\hline Ing por jubilación o pensión & 3.440 & $(*)$ & $(*)$ & 2.138 & 2.020 & 4.336 \\
\hline $\begin{array}{l}\text { Ing del Estado Monetario } \\
\text { Tekopora }\end{array}$ & 192 & 201 & 188 & 177 & 160 & $(*)$ \\
\hline $\begin{array}{l}\text { Ing del Estado Monetario } \\
\text { Adulto Mayor }\end{array}$ & 604 & 559 & 656 & 614 & 589 & 536 \\
\hline Otros ingresos $^{2}$ & 675 & 189 & 182 & 243 & 383 & 2.930 \\
\hline $\begin{array}{l}\text { Promedio de Ingreso familiar } \\
\text { disponible }^{3}\end{array}$ & 5.015 & 1.273 & 2.309 & 3.289 & 4.638 & 10.804 \\
\hline
\end{tabular}

Fuente: DGEEC. Encuesta Permanente de Hogares 2017

${ }^{1}$ No incluye ingresos igual a cero.

${ }^{2}$ Incluye ingresos provenientes de otros ingresos agrícolas anuales, pensiones o prestaciones por divorcio o cuidado de hijos,

alimentación escolar, alquileres o rentas e intereses

3 No incluye la renta imputada de la vivienda propia y el ingreso de empleados domésticos en el hogar.

a un servicio asistencial a pesar de alguna enfermedad o accidente, refuerza el argumento de la fragilidad de la cobertura del sistema.

Los problemas del sistema nacional de salud y las condiciones extendidas de desprotección social llegan al punto que, en regiones de frontera, una magnitud considerable de paraguayos recurre a los servicios asistenciales de salud de países vecinos, revelandola exclusión social territorial que interpela la legitimidad de una pretensión nacional del Estado (Galeano, 2017).

En suma, la asistencia de salud constituye uno de los servicios al que la población es más sensible, en especial aquellos sectores sociales sin capacidad adquisitiva para enfrentar los riesgos a los que se exponen en situaciones de morbilidad. ${ }^{12}$ Ante una crisis pandémica (v.gr. COVID-19), reluce la fragilidad de los sectores excluidos para enfrentar las contingencias, tanto de salud pública como de las necesidades más elementales de alimentación y cuidados.

La problemática de la salud pública,

12 Entre los gastos pecuniarios se incluyen los destinados a transporte y alimentación porque aun si no afectan directamente los tratamientos y hospitalización, implican gastos a los hogares ante situaciones eventuales de enfermedad o accidentes. "La composición del gasto bolsillo en salud se concentra principalmente en el rubro medicamentos $(43,3 \%)$, seguido por los gastos destinados a exámenes de laboratorio y radiografías $(16,7 \%)$, los gastos en hospitalización e internación (16,3\%), gastos en transportes $(9,8 \%)$ y cada uno de los gastos destinados a consultas, comidas y otros (5\%). No se puede dejar de mencionar que el alto nivel de automedicación tiene una innegable incidencia en el porcentaje del gasto (Zavattiero, 2019, p. 70). 
expresadaenun sistemaasistencialdisperso, segmentado y fragmentado, se explica por la extrema fragilidad y vulnerabilidad de los sectores sociales que demandan los servicios: excluidos de la solidaridad social institucionalizada, esos sectores son los más vulnerables a caer en los tentáculos del clientelismo, desmovilizando sus luchas y proclives a constituirse en objeto del control social. Este es el caso en la política social vigente dado que, el sector excluido del mercado de trabajo e identificado como población en situación de pobreza, es beneficiario de programas públicos de asistencia social que inciden endeblemente en su promoción social. Inscriptos en los modelos de focalización, permiten las condiciones de clientelismo y monopolio de la política pública para fines políticos.

\section{Solidaridad institucional y acción colectiva: claves para el cambio estructural.}

Con el somero repaso de las relaciones estructurales, se puede entender que la fragilidad de la política de bienestar no es un problema económico sino un problema político. No sólo hay recursos para la inclusión social y la atención ante la contingencia, sino que son ingentes.

A juzgar por la distribución del ingreso del año 2018, según la cual la media de los ingresos familiares de la población del quintil más rico equivalía a casi tres veces más que el mismo tipo de ingresos de la población reunida de los dos quintiles más pobres, podemos hacernos una idea del potencial redistributivo de la estructura social (Tabla 2). ${ }^{13}$

Actuando como fuerzas activas de estructuración del Estado, las clases propietarias se organizan en un espacio de posibilidades cuyo límite se imponecadavez más como un problema de legitimidad de la estructura de poder que ellos contribuyen a

13 Demás está decir que la población del percentil más rico, cuya fortuna es desmesuradamente superior al resto de la sociedad, tiene bajas probabilidades de selección en la muestra de las encuestas de hogares. sostener: la creciente intolerancia social a los privilegios y a la desigualdad.

Sólo que, hasta ahora, las clases populares, en tanto fuerzas potenciales de cambio, no articularon una propuesta hegemónica de acción colectiva tendiente a modificar en su totalidad la estructura de poder. Flanqueados también por sus necesidades y contradicciones, se movilizan de forma fragmentada y sin impugnar directamente los privilegios de las clases propietarias. Es decir, la presión social no se traduce en acciones colectivas encaminadas a impugnar el núcleo duro de las relaciones de poder: la estructura fiscal.

Ante la falta de acciones contenciosas para la transformación de la fiscalidad, la solidaridad social continúa a tomar su típica forma ambivalente: por una parte, moviliza la reciprocidad a nivel comunitario, sea en formas de recaudación emergencial o de altruismo impuesto (Dobrée, 2019, p. 121) con un débil impacto en la previsión integral de los riesgos; por otra parte, fortalece la ideología propietarista en que la protección social es gasto, no inversión.

No vendrá a las clases propietarias cual epifanía tomar conciencia de su compromiso histórico de tributaren favor de una política de bienestar para la población paraguaya. Requiere del recurso coercitivo del poder público. Asimismo, no vendrá a las clases populares como maná del cielo el reconocimiento de sus derechos por el Estado. Es necesario articular las demandas sociales en acciones colectivas que apunten al cambio de la estructura fiscal.

La instauración y funcionamiento de un sistema de protección social por la vía de un sistema redistributivo de financiamiento es consustancial con un sistema impositivo progresivo. Por lo tanto, un sistema de protección social no puede, por un principio básico de soberanía, basar su financiamiento en el endeudamiento. Ello significaría dimitir ante la voluntad de las clases propietarias de desligarse de su responsabilidad pública y su deuda histórica.

Desmontar la estructura deprivilegios de clase es la condición de posibilidad de 
un Estado democrático, donde rijan los derechos y adquiera institucionalidad pública la justicia social.

\section{Conclusión}

La situación real de las condiciones de bienestar en Paraguay pudo constatarse durante la emergencia sanitaria debido a la pandemia por Coronavirus, desnudando la incapacidad del Estado para atender la incertidumbre y los riesgos por la interrupción de la actividad económica general, afectando especialmente a los trabajadores y los hogares dependiente del segmento informal del mercado de trabajo.

La incapacidad del Estado es la expresión de su captura por los sectores sociales dominantes para eludir su obligación tributaria, pero no solamente. Esa captura está orientada sobre todo a sostener un modelo regresivo del sistema impositivo, según el cual la irrisoria contribución fiscal de las clases dominantes se traduce en la transferencia de la responsabilidad de financiamiento del funcionamiento de la administración, de las políticas públicas y del desarrollo, quede a cargo de sectores sociales intermedios y las clases desfavorecidas. Esta estructura fiscal que favorece, incluso promueve, privilegios y restringe derechos, es la traducción institucional de la estructura social paraguaya, caracterizada por elevados niveles de concentración económica y desigualdad entre las clases sociales. Estructura de privilegios que, por definición, no cambiará como efecto de su propia dinámica.

Es aquí donde la interpelación desde la sociedad, más específicamente, desde los sectores sociales desfavorecidos y los intermedios, de vocación democrática, requieren anteponer estrategias de acción colectiva por la reforma de la estructura fiscal, primer paso, ineludible, para la democratización de la estructura social. Es aquí también donde, por medio de las movilizaciones, la democracia adquiere su verdadero significado: un régimen de gobierno que allana el avance hacia derechos cuyo ejercicio es garantizado por el Estado

\section{Referencias}

Abente, D. (2012). Estatalidad y calidad de la democracia en Paraguay. América Latina Hoy, 6o, pp. 43-66.

Barreix, A. (2016). Experiencias y prácticas internacionales de tributación. BID.

Borda, D., \& Caballero, M. (2018). Una reforma tributaria para mejorar la recaudación y la equidad. CADEP.

Borda, D., \& Caballero, M. (2017). Desempeño e institucionalidad tributaria en Paraguay. CADEP.

Borda, D., \& Caballero, M. (2016). Eficiencia $y$ equidad tributaria. Una tarea en construcción. CADEP.

Dobrée, P. (Ed.). Usos del tiempo y desigualdades en Paraguay. CDE.

Duarte, R. (2017). Capacidades estatales para la lucha contra la pobreza en el Paraguay. (Tesis de Maestría). Inédito.

Elias, N. (2011). El proceso de civilización. Fondo de Cultura Económica.

Dirección General de Estadística, Encuestas y Censos. (2018). Principales resultados de pobreza monetaria y distribución del ingreso EPHC 2018. DGEEC.

Galeano Monti, J. (2017). Territorios de exclusión social. Arandurâ

García, S. (2015). La protección social en Paraguay: conexiones históricas para entender el presente. Revista de Investigación en Ciencias Sociales, 2(3).

Masi, F. (2018). Consideraciones sobre la contribución impositiva. En M. Rivarola (Ed.), Fiscalidad para la Equidad social. Decidamos/CADEP.

Marx, K. (1959). El capital. Crítica de la economía política. Fondo de Cultura Económica.

Ortiz, L. (2016). Desigualdad y clases sociales. Estudios sobre la estructura social paraguaya. CEADUC/CLACSO/ ICSO. 
Palau, M. (2016). La clase: más que estructura, una relación de explotación. En L. Ortiz (Ed.), Desigualdad y clases sociales. Estudios sobre la estructura social paraguaya. CEADUC/CLACSO/ ICSO.

Piketty, T. (2019). Capital e ideología. Deusto.

Rodríguez José C. (2019). Fiscalidad y extractivismo en Paraguay. Propuesta de cambio tributario para el desarrollo, la inclusión, la equidad y la prosperidad. FES.

Schuster, C. (2013). Clientelismo y el juego político de profesionalización del empleo público en Paraguay.CADEP.
Serafini, V, Imas, V., Riera, F., \& Montalto, B. (2019). La protección social en el Paraguay. Objetivos de Desarrollo Sostenible 2030. CADEP.

Serafini, V. (2017). Elites y captura del Estado. Paraguay: un estudio exploratorio. Decidamos.

Weber, M. (1964). Economía y Sociedad. Fondo de Cultura Económica.

Zavattiero, C. Fantin, A., Zavattiero Tornatore, G. (2019). Demandas potenciales en salud y cuidados desde los cambios en la dinámica demográfica en Paraguay. ICSO.

\section{Sobre el Autor}

Luis Ortiz

Sociólogo. Doctor en Sociología por la Escuela de Altos Estudios en Ciencias Sociales (Francia) y Máster en Ciencias Sociales por la Facultad Latinoamericana de Ciencias Sociales (México). Autor de 9 libros y más de 50 artículos de publicación nacional a internacional. Fundador e investigador del Instituto de Ciencias Sociales de Paraguay (ICSO). Dirige la Revista de Investigación en Ciencias Sociales (REVICSO). Fue académico visitante en The New School University, de Nueva York (USA), durante el año académico 2018-2019. Docente de la Facultad de Ciencias Sociales (FACSO), UNA, y de la Facultad Latinoamericana de Ciencias Sociales (FLACSO), sede Paraguay. Investigador categorizado del Programa Nacional de Incentivo a la Investigación (PRONII), Nivel II. 